\title{
COMPARISON OF THE EFFECTS ON SPINAL REFLEXES OF ACETYLSALICYLATE AND METAMIZOL IN SPINALIZED AND NORMAL RATS
}

\author{
Osman Genç ${ }^{1}$, Sebahat Turgut ${ }^{1}$, Günfer Turgut ${ }^{1}$, Selim Kortunay ${ }^{2}$ \\ Pamukkale University, Faculty of Medicine, Denizli, Turkey: Department of Physiology ${ }^{1}$, Department of Pharmacology ${ }^{2}$
}

\begin{abstract}
Summary: The effects of nonsteroidal antiinflammatory drugs, acetylsalicylate and metamizol, on spinal monosynaptic reflexes were investigated in spinalized and normal rats. Adult rats $(n=36)$ weighing $150-200 \mathrm{~g}$ were anesthetized with ketamine and artificially ventilated. Half of rats were spinalized at $\mathrm{C} 1$ level. A laminectomy was performed in the lumbosacral region. Following electrical stimulation of the sciatic nerve by single pulses, reflex potentials were recorded from the ipsilateral L5 ventral root. Acetylsalicylate was administered orally $(100 \mathrm{mg} / \mathrm{kg}$ for both spinalized and normal rats). Metamizol was administered intramuscularly ( $15 \mathrm{mg} / \mathrm{kg}$ for both spinalized and normal rats). These drug administrations significantly decreased the amplitude of reflex response in all groups $(\mathrm{p}<0.05)$. These data verify that observed inhibition by acetylsalicylicate and metamizol may be at the level of spinal cord. Also we suggested that the cyclooxygenase products of arachidonic acid may play an important role in regulating the reflex potential.
\end{abstract}

Key words: Acetylsalicylate; Metamizol; Spinal reflexes; Spinalized rat; Normal rat

\section{Introduction}

Reflex is the simplest form of behavior. In order to clarify the pharmacologic and physiologic basis of monosynaptic and polysynaptic reflexes, lots of studies have been performed $(5,7,8,14)$.

Acetylsalicylate and metamizol which are nonsteroidal antiinflammatory drugs (NSAI's), inhibit cyclooxygenase (COX) to reduce the production of prostaglandin, prostacyclin and thromboxan $A_{2}(4,5,12)$. The analgesic effects of two drugs have also been investigated extensively. In humans, acetylsalicylate effectively reduces pain produced by electrical stimulation of the tooth pulp (2). Also intrathecal administration of lysine-acetylsalicylate (LAS) reduces pain perception in cancer patients (3). In another study it was found that the activity in rat thalamus neurones, evoked by electrical stimulation of nociceptive afferents, is depressed by metamizol (dipyrone) and LAS (1). The inhibitory changes induced in the corneal reflex by administration of LAS depend on central mechanisms (5).

In our previous study, we reported that acetylsalicylate and metamizol significantly decreased the amplitude of monosynaptic reflex response in the spinalized rats (8). But in the normal rats the situation was unknown. For this reason we aimed to clarify the effects of these drugs on the monosynaptic reflex amplitude in the normal rats.

\section{Materials and method}

Thirty six Wistar albino rats were supplied from the Animal Care Unit within Pamukkale University Animal Research Centre, Turkey. They were reared under the supervision of a veterinarian, and kept in a well-ventilated, noiseless environment and allowed free access to food and water.

Rats, weighing 150-200 g, were anesthetized with ketamine ( $50 \mathrm{mg} / \mathrm{kg}$, i.m., Parke Davis, Istanbul, Turkey). The half of the animals were spinalized at C1 level. Laminectomy was performed in the lumbosacral region for all rats. The ventral roots of segment L5 were isolated and a pouch of skin formed at the site of the dissection in order to allow the exposed tissues to be covered with liquid paraffin. The temperature was kept $36 \pm 0.5^{\circ} \mathrm{C}$ with a heating pad.

The sciatic nerve was isolated after the dissection of left thigh region. The sciatic nerve was placed on a silver-silver chloride wire electrode for stimulation $(0.2 \mathrm{~Hz}, 0.2 \mathrm{~ms}$ duration, $5 \mathrm{~mA}$, single pulse; data acqusition system, dual BIO Amp/Stimulator, PowerLap/8SP, ADInstruments, Castle Hill, Australia) through an isolation unit. Reflex potentials were recorded from the ipsilateral L5 ventral root, mounted on a silver-silver chloride wire electrode (data acqusition system, Dual BIO Amp/Stimulator, PowerLap/8SP). 
Before recording of reflex potentials, control recordings were obtained following the application of the solvents without drugs (acetylsalicylate, metamizol). Acetylsalicylate tablet (Dispril, Reckitt and Colman Products, Slough, UK) were dissolved in water and administered orally (100 $\mathrm{mg} / \mathrm{kg}, \mathrm{n}=6$, for spinalized rats; $100 \mathrm{mg} / \mathrm{kg}, \mathrm{n}=6$, for normal rats) via a nasogastric tube. A parenteral solution of metamizol sodium (Novalgin, Aventis, Istanbul, Turkey) was administered intramuscularly $(15 \mathrm{mg} / \mathrm{kg}, \mathrm{n}=6$, for spinalized rats; $15 \mathrm{mg} / \mathrm{kg}, \mathrm{n}=6$, for normal rats). After drug applications, recordings were performed for every $15 \mathrm{~min}$ from 5 th to the 180th min. Reflex amplitudes are expressed as a percentage of the value just prior to drug administration and were compared with control recordings.

The administrations of $0.9 \%$ of $\mathrm{NaCl}$ solution were performed orally $(n=6)$ and intramuscularly $(n=6)$ in a group of rats. The same recording process of reflex potentials was also performed this group.

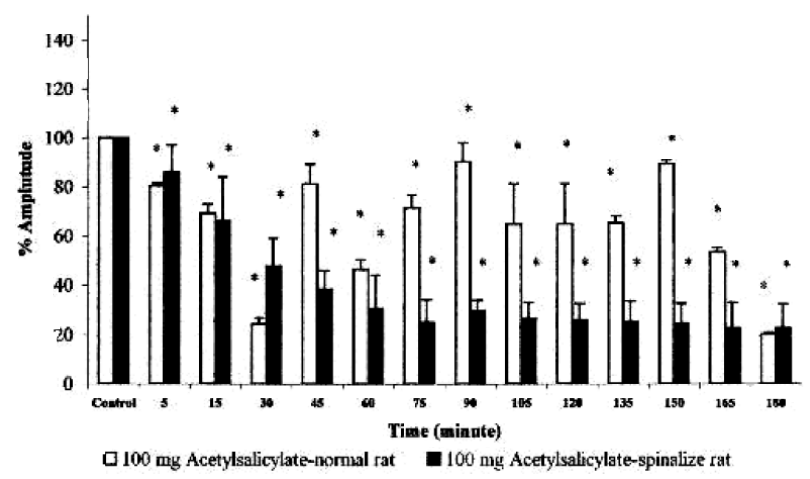

Fig. 1: Effects on reflex amplitudes of acetylsalicylate given orally to spinalized and normal rats. Drugs were applied at 0 min. The reflex amplitude (means \pm SD of 6 experiments) is expressed as a percentage of the value just prior to drug administration. ${ }^{*} \mathrm{p}<0.05$, Wilcoxon signed ranks test.

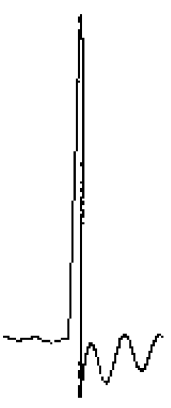

A

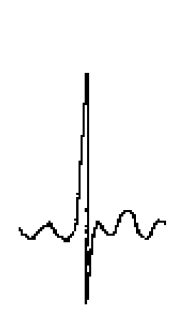

B

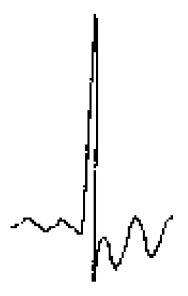

C

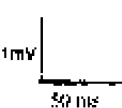

Fig. 2: Effects on reflex responses of $100 \mathrm{mg} / \mathrm{kg}$ doses of acetylsalicylate given orally to the normal rats. Control (A), and the reflex potential recordings after 60 (B) and 135 (C) min. Reflex potential amplitudes were decreased significantly in these times $(\mathrm{p}<0.05$, Wilcoxon signed ranks test).
Results were expressed as means \pm SD. Statistical analysis were made with the Wilcoxon signed ranks and MannWhitney $U$ tests. $p<0.05$ was considered significant.

\section{Results}

The $100 \mathrm{mg} / \mathrm{kg}$ doses of acetylsalicylate significantly decrease the reflex response amplitude of at the 30-, 45-, 60-, 75-, 105-, 120- and 135- min recordings in normal and spinalized rats $(p<0.05$; Fig. 1$)$. When the effects of the acetylsalicylate $(100 \mathrm{mg} / \mathrm{kg})$ was compared, the decreases in reflex response amplitude at of 45-, 60-, 75-, 90-, 105-, 120-, 135-, 150- and 165- min recordings in spinalized rats were significantly higher than those of normal rats $(\mathrm{p}<0.05$; Fig. 1). Figure 2 shows the effects of $100 \mathrm{mg} / \mathrm{kg}$ dose of acetylsalicylate given orally to the normal rats. Figure 2 shows the control and 60- and 135- min results after drug administration.

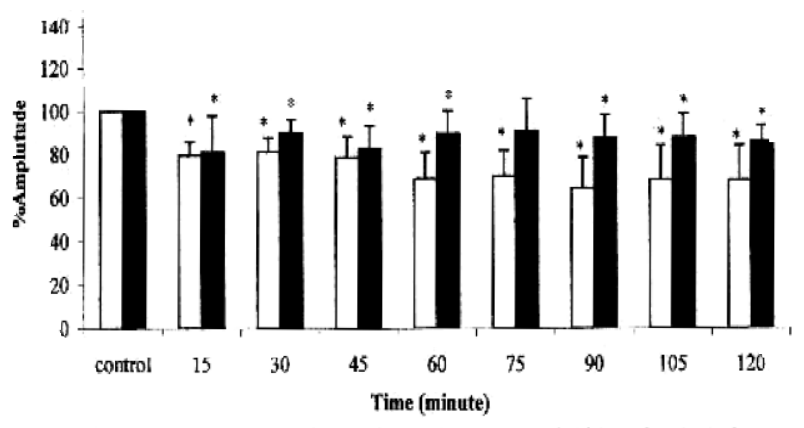

$\square 15 \mathrm{mg}$ Metamizol sodium to the norimat rat $\mathbf{U} 15 \mathrm{mg}$ Metamizol sodnun to the spinalized rat

Fig. 3: Effects on reflex amplitudes of metamizol given intramuscularly to the spinalized and normal rats. Drugs were applied at $0 \mathrm{~min}$. The reflex amplitude (means \pm SD of 6 experiments) is expressed as a percentage of the value just prior to drug administration. Significant differences as compared with controls $\left({ }^{*} \mathrm{p}<0.05\right.$, Wilcoxon signed ranks test).

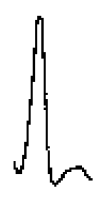

A

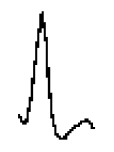

B
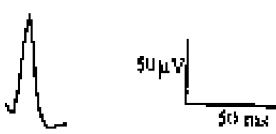

$\mathrm{C}$
Fig. 4: Effects on reflex responses of $15 \mathrm{mg} / \mathrm{kg}$ doses of metamizol (i.m.) in normal rats. Control (A), and the recordings after 45 (B) and 120 (C) min. In these records, the decrease in reflex response amplitude was significant $(\mathrm{p}<0.05$, Wilcoxon signed ranks test). 
The group administered orally a solution of $0.9 \%$ of $\mathrm{NaCl}$, had no significant change in reflex response amplitude with respect to the control group ( $p>0,05)$.

The $15 \mathrm{mg} / \mathrm{kg}$ doses of metamizol also significantly decreased the reflex response amplitude of all of the recordings in normal and spinalized rats (Fig. 3, p<0.05). But there was no change in the latency (Fig. 4). Figure 4 shows effects of $15 \mathrm{mg} / \mathrm{kg}$ dose of metamizol given intramuscularly to the normal rats. We detected only significant inhibition differences between normal and spinalized groups on the reflex amplitude response at the 60-, 75-, 90-, 105- and 120- min recordings ( $\mathrm{p}<0.05$; Fig. 4).

The group administered intramuscularly a solution of $0.9 \%$ of $\mathrm{NaCl}$, had no significant change in reflex response amplitude with respect to the control group $(p>0,05)$.

\section{Discussion}

Prostaglandins are synthetized in the brain and spinal cord. But it is unknown that whether prostaglandins have any role in the synaptic transmission of nociceptive stimulus. NSAID's like acetylsalicylate and metamizol, via the inhibition of cyclooxygenase (COX) enzymes, inhibit synthesis of prostaglandin in the brain, spinal cord and many other tissues.

The increase in the synthesis of local prostaglandins which cause hyperalgesia in the rat claw model was shown (6). But, there is no consensus, whether pain has a central component, which is based on the increase in the synthesis of prostaglandins in the central nerve system. The entrance of calcium to neuronal axons and nerve endings, stimulate synthesis and release of prostaglandins. It was well-known that the peripheral stimulation of afferent nerve endings with electrical and other irritant factor caused increased release of prostaglandins. The released prostaglandins cause neuromediator release in the synapsis of sensorial nerve endings coming from periphery and facilitated neurotransmission in spinal cord level. Schweizer and Brom (12) found that diclofenac-Na, acetylsalicylate and paracetamol abolished the algesic effect of bradykinin in the presence and absence of prostaglandin $\mathrm{E}_{2}$. In addition in mentioned study, NSAID's were able to inhibit the nociceptive responses to bradykinin in the presence of exogenous prostaglandin $E_{2}$. Based on these findings it was suggested that these compounds may have an additional unrelated effect on bradykinin-mediated pain responses besides their inhibition of the COX system (12). Jurna et al. (11) proposed that intrathecal injections of acetylsalicylate interfere with prostaglandin synthesis in the spinal cord, thus reducing onward transmission of noxious stimuli within the nociceptive system. If this is so, piroxicam and LAS may have suppressed the corneal reflex by exerting inhibition on the reflex arc at the level of the spinal trigeminal nucleus pars caudalis and subjacent lateral reticular formation (5). Gühring et al. (10) explored that the synthetic cannabinoid (HU-210) induced prostaglandin $\mathrm{E}_{2}$ synthesis simultane- ously to its antinociceptive effect at the spinal level. In the other study, Gühring et al. (9) showed the involvement of endocannabinoids in the indomethacin-induced antinociception at the spinal level. Siedel et al. (13) investigated a possible involvement of endocannabinoids in flurbiprofen-induced inhibition of spinal calcitonin gene related peptide (CGRP) release using the spinal superfusion model. They suggested that their study provides evidence of the shift in arachidonic acid metabolism towards endocannabinoid formation in response to COX inhibition as a mechanism for the flurbiprofen inhibitory effect on spinal CGRP release.

In our previous study, we reported that acetylsalicylate and metamizol significantly decreased the amplitude of monosynaptic reflex response in the spinalized rats (8). But in the normal rats the situation was unknown. In this study, we used spinalized and normal rats so that the evaluation of the simple, monosynaptic ipsilateral reflex potential response. According to our results, the significant decreases after the acetylsalicylate and metamizol applications in the reflex responses must be related with the inhibition of COX enzymes at the level of spinal cord. Because we determined significant decreases in the reflex response both of spinalized and normal rats after acetylsalicylate applications. On the other hand, at the same drug dose level, we found the more significant inhibiton in the spinalized rats than in the normal rats, because of the loss of the effects of supraspinal centers.

In conclusion, acetylsalicylate and metamizol which show their effects at the spinal and supraspinal level, inhibit the monosynaptic reflex response amplitude. In these effects, COX inhibition may be a possible mechanism.

\section{References}

1. Carlsson KH, Monzel W, Jurna I: Depression by morphine and the non-opioid analgesic agents, metamizol (dipyrone), lysine acetylsalicylate, and paracetamol, of activity in rat thalamus neurones evoked by electrical stimulation of nociceptive afferents. Pain 1988; 32: 313-326.

2. Chen ACN, Chapman CR: Aspirin analgesia evaluated by event-related potentials in man: possible central action in brain. Exp Brain Res 1980; 39: 359-364.

3. Devoghel JC: Small doses of lysine-acetylsalicylate relieve intractable pain in man. J Int Med Res 1983; 11: 90-91.

4. Ergün H, Uzbay T, Çelik T, Kayir H, Yeşilyurt Ö, Tulunay C: Dipyrone inhibits ethanol withdrawal and pentylenetetrazol-induced seizures in rats. Drug Dev Res 2001; 53: 254-259

5. Ferracuti S, Leardi MG, Cruccu G, Fabbri A, Itil TM: Analgesic-antiinflammatory drugs inhibit orbicularis oculi reflexes in humans via a central mode of action, Prog Neuropsycho-pharmacol Biol Psychiatr 1992; 18: 101-113.

6. Ferreira SH: Prostaglandins: Peripheral and central analgesia; in Bonica JJ (ed): Proceeding of the Third World Congress on Pain. Advances in Pain Research and Therapy. New York, Raven Press, 1983, vol 5, p 627.

7. Genç O, Demir S, Tasci N, Kaptanoglu B, Marangoz C: The effects of calcium channel blocker, flunarizine, on spinal reflexes in the cats. Acta Physiol Pharmacol Ther Latinoam 1999; 49: 119-123.

8. Genç O, Turgut S, Turgut G, Kortunay S: Inhibition of spinal reflexes by acetylsalicylate and metamizol (Dipyrone) in rats. Pharmacology 2003; 69: 123-126.

9. Gühring H, Hamza M, Sergejeva M, Ates M, Kotalla CE, Ledent C, Brune K A role for endocannabinoids in indomethacin-induced spinal antinociception. Eur J Pharmacol 2002; 454: 153-163.

10. Gühring H, Schuster J, Hamza M, Ates M, Kotalla CE, Brune K: HU-210 shows higher efficacy and potency than morphine after intrathecal administration in the mouse formalin test. Eur J Pharmacol 2001; 429: 127-134. 
11. Jurna I, Spohrer B, Bock R: Intrathecal injection of acetylsalicylic acid, salicylic acid and indomethacin depresses $\mathrm{C}$ fibre evoked activity in the rat thalamus and spinal cord. Pain 1992; 49: 249-256.

12. Schweizer A, Brom R: Differentiation of peripheral and central effects of analgesic drugs. Int J Tissue React 1985; 7: 079-083.

13. Seidel K, Hamza M, Ates M, Gühring H: Flurbiprofen inhibits capsaicin induced calcitonin gene related peptide release from rat spinal cord via an endocannabinoid dependent mechanism. Neurosci Lett 2003; 338: 99-102.

14. Yamazaki J, Ono H, Nagao T: Stimulatory and inhibitory effects of serotonergic hallucinogens on spinal mono- and polysynaptic reflex pathways in the rat Neuropharmacology 1992; 31: 635-642.

Submitted March 2004.

Accepted May 2005.

Osman Genç, M.D., Ph.D.,

Pamukkale Üniversitesi Tip Fakültesi Fizyoloji A.D., P.K. 3320020 Denizli,

Turkey.

e-mail:ogenc@pamukkale.edu.tr 